\title{
Analysis of Enterprise Management Mode under Market
}

\section{Economy Condition}

\author{
Yuhan Guo ${ }^{1 *}$ \\ ${ }^{1}$ Graduate management Team, Logistics University of PAP, Tianjin, China \\ *Yuhan Guo, E-mail: 752191130@qq.com
}

Received: June 6, 2017

doi:10.22158/jbtp.v5n3p194
Accepted: June 18, $2017 \quad$ Online Published: June 22, 2017

URL: http://dx.doi.org/10.22158/jbtp.v5n3p194

\begin{abstract}
Economic mode is the basis of the development of enterprise management mode. Ecotype circular economic model is the most ideal model of 21st century, which mainly realizes management innovation and management planning of modern enterprise under circular economy through evolution process analyzing of modern enterprise management mode. Cross and amalgamation management model is the objective requirement of circular economy development under enterprise economy conditions. With social economic development and change of economic model, enterprise management mode must achieve thorough revolution for further development. Therefore, effective management mode of enterprise has become the only way to healthy develop 21 st economy.
\end{abstract}

\section{Keywords}

circular economy, enterprise management mode, cross and amalgamation management

\section{Introduction}

Since the reform and opening up, the development of circular economy under the condition of market economy has always been the focus and hot issue of the insiders. Under the background of reform of the economic system, the key factors of enterprise management mode are dramatically influenced by management system and shift from the planned economic system to the modern market economic system reform. Therefore, the corporate management has been transferred from the traditional micro-management to the macro-control of indirect management. With China's macro-control has further turned into the independence Efficiency mode from low to high instead of a stand-alone dependency and the emergence of non-institutional factors, China's enterprise management model presents new changes.

\section{Changes about China's Enterprise Management Model}

Enterprise management mode refers to: the enterprise managers uniformly manage the staff with the enterprise's method such as organization and command, incentive mechanism according to the enterprise's values in the enterprise management practice. It combines the management guidance of business system, control methods, the leadership style of business management group, the enterprise incentive system organically in order to meet the needs of the market products and services, make the best of the resources' maximum advantages and benefits, achieve business management target as soon as possible.

Enterprise management model is built on the basis of modern enterprise management. With the continuous development and innovation of science and technology, according to the development of 
modern theory, enterprise management model can be divided into: the traditional rational management stage, the irrational management stage, the management stage of irrational and rational integration, the organizational management stage under the knowledge economy era.

\subsection{The Traditional Rational Management Stage}

Mainly focus on the aspect of management functions and organizational form so as to increase efficiency, the traditional rational management stage aims to achieve the objectives and efficiency of the enterprises gradually by formulation process of production technology, management processes and management agencies.

\subsection{The Irrational Management Stage}

Stress the full use of the enterprise's purpose, reputation, value criteria and norms, this stage pay attention to soft management factors, and improve the cohesion of enterprise workers through cultivating corporate culture.

\subsection{The Management Stage of Irrational and Rational Integration}

This enterprise management model mainly stressed the innovation in the organization, culture, process and system of the enterprise management system, especially the operating process that the rational management procedures are most concerned.

\subsection{The Organizational Management Stage under the Knowledge Economy Era}

The only source of competitive advantage of the enterprise is their enterprise's technological capability are better and faster than competitors. The learning staff can regain the meaning of life at work, realize the common goal and aspiration of their enterprise and ensure that the organization can obtain the competitive advantage.

\section{The Establishment of Enterprise Management Model}

With the development of modern enterprise management theory, the scientific and technological theory under the modern science and technology revolution has made progress. That has greatly influenced the enterprise management. Meanwhile, the development process of the modern enterprise management mode is dynamic. The modern enterprise management mode is in the process of discovery and formation, but a variety of management system has been initially established, and have a clear goal. Therefore, the barriers affecting enterprise management system gradually lifted and non-institutional factors of enterprise management model began to rise. Various factors like computer and network information management prominent especially after China's accession to WTO. It is an all-round, thorough and revolutionary impact, just like the steam engine's effect on the operating mechanism and development trend of enterprise in the industrial revolution. The following is the analysis for different enterprise management models:

\subsection{Simple Management Model of Division of Labor}

Division of labor is not only a sign of social progress, but also an important measure to further improve the efficiency of enterprises. Under the fierce economic market environment, the manufacturing enterprises have an under-ripe create stage compared with other smaller enterprises. Thus, they tend to adopt a simple management model of division of labor. In the aspect of personnel, capital, assets, supply demand, production and sales, enterprises prefer to take the operation of this value chain in series.

\subsection{Integrated Management Model of Division of Labor}

Owing to the rapid update of science and technology and the thorough development of the industrial economy, the division of labor are becoming more and more detailed, but over-division of labor is easy to make trivial business processes, increased management level, information sharing being hindered, which 
will make negative impact of workers' active creativity. And worse still, it will restricting the circulation and dissemination of interior and external information, greatly reducing the market response capacity of enterprises. When the market competition or the scale of the enterprise grows to a certain extent, what the enterprise have to do is turn their management model into an integrated management model of division of labor, the important part of which is resources management and ability management. The basic elements of resource management includes management of asset and material, planning and management of financial funds, information management, human resources and so on. The basic elements of capacity resource management includes resource supply, manufacturing, technology research and development, market development, quality of service and marketing and so on.

\subsection{Integrated Management Model}

With the rapid development of science and technology information, integrated technology of modern technology applications are becoming more and more widely spread. Based on advanced technology resources, the enterprise model achieve the expansion and sublimation, thus integrated management model has great inclusiveness and scalability. It gradually form a management model with strong vitality under fluxion and development. This management model will bring about bigger market development space and imaginary space to the enterprise.

\section{The New Economic Model for Sustainable Development}

World economic development process shows that when a country with a per capita GDP in the $\$ 500$ to $\$ 3,000$ stage of development, population, resources and environment has a higher incidence of bottleneck stage. China is currently in that period of development. Since the reform and opening up, our national energy consumption doubled so that the GDP quadrupled. Economic growth with extensive mode speed up our overall ecological environmental deteriorate. Meanwhile, eutrophication result in heavy pollution of urban environment, with serious air pollution and constantly expanding acid rain area. Such phenomenon shows that the traditional mode of economic growth must be changed accordingly. We should develop a circular economy model in accordance with the requirements of Scientific Outlook on Development, so as to timely solve harms in the aspect of economic, environmental, and resources caused by the ecological environment deterioration and resource use hazards, and ensure that our economic society can enter a virtuous circle system of sustainable development. The following is the analysis of four basic characteristics of the enterprises' circular economy development model under market economy condition:

\subsection{Take "Minimizing the Investment of Resources" as a Reduction Principle of the Goal of the Economic Development Model}

Resources are the output of the industrial chain, the industry should cleanly produce its products rather than make terminal governing. Minimizing the waste of energy and raw materials, especially in controlling the use of environmentally harmful resources, in order to further reduce consumption-aimed environmental pollution and waste of resources.

4.2 Take "Maximizing the Use of Waste Resources" as are Cycling Principle of the Goal of the Economic Development Model

Grasp the key links of the industrial chain, make reusable products and packaging containers in initial form. By this means the service time and service intensity can be effectively extended. On the other hand, it can maximize the utilization of resource products. 
4.3 Take "Optimizing the Eco-Environmental System" as Areorganized Principle of the Goal of the Economic Development Model

By analyzing the whole process of the development of the industrial chain, we can come to a definition that circular economy is to make a sustainable development with the optimal production, the optimal consumption and the least abandoned, which is directed against excessive waste of resources and environmental pollution resulted by a large amount of waste gas produced by mass production of traditional industries. In accordance with the natural ecological system model, the economic activities will be efficiently and orderly organized into an "reuse of resources-green industrial construction-recycling of resources" enclosed material energy cycle feedback process to achieve the economic production goal of low consumption, high quality, low waste, and further reduce the impact of economic activities on the natural environment.

\section{Conclusion}

The prospect of market economy development in the 21 st century shows that circular economy is the inevitable trend of future economic development. Under circumstance of the acceleration of economic globalization and the implementation of sustainable development strategy, the development model of modern enterprise management will improve in integration, which is an objective requirement for economic development and an inevitable choice for sustainable development strategies as well.

\section{References}

Huang, Z. J. (2014). On enterprise management model and enterprise management modernization. Journal of Wuhan Commercial Service College, 28(2), 12-16.

Liu, T. (2014). Research on evolution mechanism of enterprise management mode. Beijing: Capital University of Economic and Business.

Wei, J. R., \& Wang, Y. L. (2014). Innovation of enterprise management model in period of big data. Information System Engineering, 11(56). 